\title{
Balázs Boross
}

Erasmus University Rotterdam

Stijn Reijnders

Erasmus University Rotterdam

\section{Coming out with the media: the ritualization of self-disclosure in the Dutch television programme Uit de Kast}

\begin{abstract}
Using the media to disclose one's sexual identity has become an increasingly salient practice in recent years. Yet little is known about the reasons for the emergence of this form of self-disclosure. Based on an analysis of the Dutch television programme Uit de Kast ('Out of the Closet'), this article relates the rise of mediated coming out practices to the ritualizing power of the media: we argue that media plays a quintessential role in transforming the socially unscripted act of coming out into a patterned, culturally meaningful performance. Our analysis reveals that the ritual work of the programme is embedded in the ways 1 ) the generic format of the show structures the self-disclosures, 2) the authority of the media is deployed to channel the coming out process, and 3) the programme, while controlling diversity, reinforces dominant societal values and ideologies. The case not only highlights how unprecedented ritual forms come to flourish in the current era of 'participatory' media culture, but also demonstrates how ritualization supports and naturalizes the claim that media is an effective agent to create order in everyday, ordinary lives.
\end{abstract}

Key words: coming out; media authority; self-disclosure; ritual; factual entertainment; participation 


\section{Introduction}

In a sport pub in the Dutch town Tilburg, five young men are having beers after their game. They are not alone: there are cameras present, shooting a youth programme - allegedly - about soccer and friendship.

'Boys, I have to tell you something' - announces one of the guys, Daan, but his best friend interrupts him: 'I am gay, hahaha,' and starts clapping. Daan decides to disregard his friend's remark and continues with his prepared speech until the final words: 'I am into boys'.

'Serious?' - asks the friend, Tinus, still with a smile on his face - 'Then I can't talk with you anymore.'

The others, recognizing the seriousness of the situation, neglect their friend's response, and gradually reassure Daan about their unchanged friendship.

'But... is this real? I thought this is fake... like Candid Camera' - at this point, Tinus finally understands what is really going on and bursts into tears.

Triggered by the unexpected confession of his mate, and by the late realization of the 'reality' of a situation with which Tinus was otherwise familiar from the media, this dramatic moment was captured in the second season of the Dutch television programme Uit de Kast ('Out of the Closet'). The programme, nominated for an International Emmy Award in the category of 'Kids factual' in 2012, was launched by the public broadcasting company KRO in 2010 and finished its third season in 2013. Each of the 18 episodes centres around one protagonist who comes out 'live' to their immediate environment (family, friends and peers) with the assistance of the popular presenter Arie Boomsma. Depending on the social circumstances of the candidates, the episodes vary in the degree of awkward, cathartic and confrontational moments, but the dual mission of the show is quite explicit: helping the youngsters through a critical moment of their lives, and showing the difficulties people still face when it comes to coming out in contemporary Dutch society.

Although the longest running televised format so far, Uit de Kast is not an exceptional phenomenon: using the media to disclose one's sexual identity has become an increasingly salient practice in recent decades. Today we can witness the proliferation of examples of mediated coming out in various media platforms: such confessions are constantly being performed, narrated and reflected on in talk shows and the tabloid press, and on reality TV as well as online discussion forums, social media and video streaming sites. This growing production of and attention to public, mediated examples of coming out suggest that this form of self-disclosure has gone through a wider 'socialization' in the current age: coming out has been transformed from something merely intimate to something representational - a modern-day ritual that takes place in and through the media.

While coming out as a process has been discussed extensively in the academic literature in relation to individual identity development ${ }^{1}$, the practice of coming out in mediated contexts has received less attention. Furthermore, the little work that has been done on mediated coming out primarily focused on isolated examples of celebrity coming out practices (e.g. Dow, 2001), fictional representations (e.g. Herman, 2005) or coming out narratives (e.g. Alexander and Losh, 2010). To date, still little is known about the role of the media in actual instances of coming out performed by 'ordinary people'. On a general level, mediated coming out seems to embody the very ethos of interactivity and 
the underlying notion that media participation is a natural and effective outlet for creative and democratic self-expression (cf. Andrejevic, 2004; Jenkins, 2006; van Dijck, 2009). Yet, the question remains: how is the power of media participation reinforced and justified in the case of mediated coming out? What do the media offer to those exposing their personal struggles to a wider public?

Building on the work of Nick Couldry on media rituals (2003), this paper ${ }^{2}$ argues that the growing appeal to mediated performances is to a large extent derived from the process of ritualization, made possible by the symbolic power of the media. More in particular, we assert that the perceived authority of the media to represent and change social reality plays a pivotal role in transforming socially unscripted and therefore ambiguous actions into patterned, culturally meaningful and legitimate practices. The aim of this article is to scrutinize this transformative process, as it is explicitly presented and implicitly operates in the telling example of Uit de Kast. The core question of this paper - how does the ritualization of coming out work in Uit de Kast and what is the role of the media in this? - is addressed through an in-depth textual analysis of the three seasons of the programme, looking specifically at how the format of the show imposes a ritual structure on the self-disclosures, how publicity motivates and supports the confessions, and more generally, how the framing of coming out enables the programme to speak to and about wider societal values.

The success ${ }^{3}$ of Uit de Kast is evidenced also by its recently started international career: the programme was adopted by VTM, the largest commercial channel in Belgium and has also been sold to the German RTL2. Looking at this trend, and considering that Uit de Kast is not a unique programme in the Dutch television landscape addressing the 'serious' dimensions of the human condition ${ }^{4}$, one cannot easily dismiss the show as another outrageous reality programme building on the voyeuristic pleasure of gazing (Sumiala, 2011) or on the exploitation of those undergoing this spectacle (Andrejevic, 2004). In turn, we assert that investigating the ritual dimensions of the programme may open up more substantial questions about contemporary forms of media-related social behaviour. Situating the programme within the genre already raises some difficulties, given the production context (public service broadcasting explicitly embracing the mission of 'quality programming'), the lack of commercial character, the educational dimension (the project of opening up people's eyes to a relevant societal issue), and the ways these are brought together with the ethos of 'liveness', 'reality' and the exploitation of the possibilities of surveillance entertainment. While the programme, as we shall see, maintains connections with various genres - e.g. make-over realities and confessional television - it seems that this hybridity makes the Uit de Kast format especially powerful in claiming not only that it provides direct access to unscripted interactions and experiences of 'ordinary people', but also that media are effective means for changing one's every-day, unmediated life.

While exploring how the programme (appears to) achieve this effect, our analysis will show how such claims are derived from the process of ritualization, by which coming out becomes constructed as ritual practice. Ultimately, we will demonstrate the increasing significance of media as agents in the construction of unprecedented forms of contemporary ritual practices, arguing that such rituals - either serving to create a wider sense of commonality, aiming at social control, or functioning to tame societal conflicts -, have the capacity to manifest pressures towards order and valued ideals in society (Rothenbuhler, 1998).

The following sections will present this emerging ritualization of coming out practices in and via Uit de Kast, by analyzing the format of the program, the transformational work of the media frame, and 
the ritual significance of the show beyond the life of the protagonists. Before elaborating on our findings, we first briefly summarize the core theoretical considerations and methods that govern our analysis.

\section{Theoretical framework}

Research into the ritual dimensions of media culture has a long tradition within media studies: works addressing the ritual characteristics of the production, the consumption and the content of specific media formats and genres (e.g. Liebes and Curran, 1998; Rothenbuhler and Coman, 2005; Reijnders et al., 2007) have already shown how mediation contributes to the interpretation, legitimization and the structural re-organization of existing ceremonial events and activities. However, the more complex role media may play in ritualizing - and thereby ordering - otherwise unscripted social acts and events by displacing them into a ritual frame has received less attention (Coman, 2005: 48; cf. Couldry 2003).

We assert that mediated coming out is an especially telling phenomenon to understand this process: our study builds on the premise that coming out within Uit de Kast is not simply a media presentation of a rite - as is the case with the media representation or public broadcasting of, for instance, royal wedding ceremonies, funerals or national commemorations, which are the most obvious and the most extensively discussed types of media(ted) rituals (cf. Dyan and Katz, 1992; Rothenbuhler, 1998; Mihelj, 2008). While in these instances mediation primarily functions as an amplifier of a preexisting ritual event, in the case of mediated coming out we presume that it is precisely the media frame which allows examples of coming out to fully function as rituals, and more specifically, as rites of passage for the participants and the audience of the program alike. In supporting this premise, we will first show what problems arise with conceptualizing coming out as ritual practice when the media is not involved. Following this, we will examine how the media may work as an effective agent of ritualization.

\section{Coming out as a ritual?}

As a folk idiom, 'coming out' refers to many psycho-cultural processes and social events, but most commonly associated with the single act of declaring one's identity as gay to a person assumed to be straight (Herdt, 1992). In this respect, coming out is a transformative act, which effects both the individuals performing the self-disclosure and their social relationships. Accordingly, coming out not only implies both crisis and opportunity, but also takes place in a 'betwixt and between' stage that apparently divides the life course into 'before' and 'after'. These basic features certainly evoke analogies with rites of passage, the transition rituals negotiating turning points from one life stage to another.

Yet, conceptualizing coming out as a rite of passage is not unproblematic. As Grimes argues (2000), not every passage is a rite of passage, as far as we undergo passages but we enact rites. Rites of passage normally occur at a culturally determined time period, and the enactments follow certain prescripted patterns. In turn, coming out, in the traditional, non-media sense of the word, is commonly understood not as a single event, but rather as a protracted process (Drushel, 2010) that is 'characterized by unpredictability, starts, stops, backtracking, and denial' (Gonsiorek and Rudolph, 1991: 164-165). Given these attributes, it is not surprising that most of the coming out research predominantly focuses on other aspects, such as the psychological dimension (cf. Orne 2011). 
Nevertheless, coming out can, in some instances, take the ritual form of a rite of passage, given the right social context. Rituals, although generally associated with rigid structures, stability and tradition, are in fact constantly and consciously (re)invented, sometimes with the prerequisite of reconstituting the community as well (Grimes, 2000: 124). A plastic example of this could be the announcement we have encountered on the website of the Unitarian Church of Vancouver about the inclusion of 'coming out ceremonies' in their services ${ }^{5}$. Similarly, in his ethnographic research into the Horizon coming out support group in Chicago (1992), Gilbert Herdt convincingly argues that the youngsters joining the group go through the 'classical', formative and symbolic stages of a rite of passage, constructed and prescribed by the group leaders to the 'novices', before they get ready to integrate into the gay community and the wider society as gay individuals. In Herdt's description, the 'ritual separation' of the in-group activities from everyday life, the 'threshold symbolism' within the secret world of the community, and the emerging communitas that temporarily suspends the existing ethnic, class and gender differences of the members in the special space and time of the weekly meetings bring together all the patterns of a full-fledged liminal phase (cf. Turner, 1977) that enables ritual to do the work of transformation.

As the above examples illustrate, the ritualization of coming out requires some sort of institutional authority that normalizes the act of self-disclosure. Accordingly, if rites of passage proceed through the stages of separation from the community (or from the normal run of things), the transition into an especially formative time and space and the reincorporation back into the community (Grimes, 2006: 6), it seems that the media frame can provide a powerful, liminal context through which coming out becomes perceived and experienced as a rite of passage. To explain the ritual power of the media in this transformational process, Nick Couldry`s work on media rituals serves as a fruitful starting point.

\section{Media rituals}

Defined as 'formalised actions organised around key media-related categories and boundaries' (2003:29), the concept of media ritual is used by Couldry to grasp how the symbolic authority of the media is being constructed, maintained and naturalized in contemporary media-saturated societies. In line with Couldry's argumentation, this process can most clearly be captured in those 'special' situations when the boundaries between the otherwise separated realms of the media and non-media world are temporarily suspended: one can think, for example, of meet-and-greets with celebrities, film studio tours, or situations when 'ordinary people' act on television (cf. Reijnders et al., 2013). According to Couldry, such transgressive instances, because of their 'extraordinariness', actually naturalize and confirm the symbolic superiority of the media world, and thereby maintain the sense that the media are the primary access point to our shared social reality - this is what Couldry terms more generally the 'myth of the mediated centre'.

Since the coming out within Uit de Kast exemplifies'ordinary people' becoming part of or active shapers of the media production process, we can argue that such disclosures on a phenomenological level can be interpreted as media rituals. The programme not only offers an opportunity for 'ordinary' people to perform an 'extraordinary' mission while appearing and acting on the screen, but the diverse sample of participants ${ }^{6}$ also suggests that the intention of the producers was to address the widest social space possible, reproducing the above-mentioned myth. However, while Couldry`s explanation of 
how the authority of media institutions and the claim to their social centrality being reproduced in media-related practices may provide a general argumentation about why the notion of media participation is so powerful, little is known about how media authority actually operates, being deployed and appropriated by the actors to generate order in their practices (Couldry, 2006: 24) - in our case, coming out.

Our interest lies especially in this process of ordering: how does the show dramatize and pattern the act of coming out and how is the authority of the media deployed in this process? In this respect, the concept of 'ritualization ' is handled in this article as a prism to grasp the process of becoming: to investigate how mediation contributes to the standardization and the patterning of the ambiguous act of coming out by constructing a recurring, authoritative context with normative effects on those involved (Sumiala, 2013: 25). At the same time, we anticipate that the ritual efficiency and the authority of the media frame can not come into being in a cultural vacuum, but are tightly interwoven with wider, culturally determined power configurations, norms and ideologies (cf. Reijnders, 2010). Elaborating on these connections and how they are dramatized or implicitly reproduced in the media text may not only help us to capture how the 'myth of the mediated centre' is actually being constructed, but may also provide links to a broader conception of ritualization, understanding it as a process of framing certain activities in ways that become perceived as 'both intrinsically different from other acts and privileged in their significance and ramifications' (Bell, 2009: 219).

\section{Methods}

Following similar works on the ritual dimensions of television programmes (e.g. Reijnders et al., 2007), this article investigates the ritualizing role of the media in Uit de Kast through an interpretative, formalthematic analysis of the three seasons of the programme (cf. Kuppens and Mast, 2012). Although we acknowledge that ritualization may not be limited to the level of representation, our aim was to capture how the format of the programme channels the practice of coming out as well as what meanings of these structured actions are articulated throughout the content (e.g. how the role of media is justified in the show). The core data consisted of the 18 episodes (each of them approximately half an hour, with a total viewing time of nine hours) gathered on the programme's website ${ }^{7}$. The website not only allowed repeated viewing of single episodes, but also provided extra insights into 'behind the scenes' videos and access to related discussion forums and comments on the episodes from the audience.

We first looked at the micro-structure of the program, i.e. at single episodes, focusing on the patterns of talk and action, the dynamics of interactions in the coming out process and on the visible experiences and emotions of the participants. Furthermore, attention was paid to the explicit references to the 'ritual character' of the coming out and to the thematization of and reflections on the mediated feature of the self-disclosure by the actors involved. Finally, the analysis looked at the 'macro-structure', i.e. the programme as a whole, aiming to capture the underlying structure repeated throughout the episodes, the recurring themes and how the format changed through the seasons.

Our analysis identified three major factors as the basis of the ritualization of coming out: the ritual power of the programme lies in the ways 1 ) the generic format of the show reinforces the notion that coming out is a structured performance, fitting into a unidirectional process of becoming; 2 ) the authority of the media is deployed and temporarily suspended in the episodes; and 3) the programme 
reinforces certain societal values and ideologies while channelling and controlling diversity. We will elaborate on these findings in detail in the subsequent sections, starting with the generic ritual features of the programme.

\section{The generic format: structure and explicit ritualization}

During all three seasons, the format of the episodes follows a standard and more or less simple dramaturgy, divided into three phases: the immediate preparation of the protagonist for the coming out, the actual act of self-disclosure and, finally, the presentation of the consequences of the act, reflected in the reaction of the environment. This generic structure, however, becomes sequential in several episodes, since in most cases the candidates go through at least two challenges, coming out in different realms - generally to their families and separately to their peer groups.

Beyond the obvious purpose of introducing the candidates, the first, 'preliminal' phase also serves to capture the stakes of the forthcoming disclosure. In this stage, the protagonists talk about the history of their struggles and their fears about the consequences - generally, losing their family or their friends - of their coming out. These talks not only take place in the 'out of ordinary' space created by the camera presence, but the 'ritual separation' is often also spatial: the presenter Arie Boomsma meets several candidates 'in the biggest secret', far from their homes. During these discussions, the presenter tries to calm down the remarkably nervous candidates, while doing his best to maintain the suspense and highlight the risks of the forthcoming act in the case of more optimistic candidates, or when the participants get more confident after taking the first - normally 'easier' - challenge: 'What will you do if you get negative reactions?' 'Yesterday it went OK. But now the situation will be more tough, right?'

In the meantime, the important people around the candidates are interviewed. In order not to spoil the surprise factor of the actual coming out - or, as it is narrated in the episodes, 'in order to get honest reactions' - there is always a 'cover story' employed to conceal the real reason of the filming, varying according to the individual circumstances of the protagonist: the shooting is said to be about religious youth, about sport and friendship, or about student life. These interviews normally address how the parents or the closest friends see the protagonists, yet the underlying aim is to figure out the attitudes regarding homosexuality and whether the environment suspects anything about the 'secret' of the candidates.

After setting the stage this way, it is time for the candidates to enter the central, 'liminal' stage of their endeavour. If the candidate seems to be confident enough, Arie stays 'behind the scenes'. However, even such protagonists lose their courage in the last moment - in these cases the youngster leaves the scene for a while and draws strength from the encouraging words of Arie: 'Just go and tell. Say: guys, I have to tell you something... and go!' Due to such instructions, and because the candidate is forced to practice the phrasing of the disclosure in advance (Arie always asks beforehand: 'How are you going to do it?'), the actual coming out speeches are remarkably short, sometimes no more than a few sentences. Accordingly, more emphasis is placed on the presentation of the direct reactions of the environment and on how all the parties 'digest' the announcement. When the reactions are positive, Arie immediately takes the lead to discuss how the disclosure was experienced by the confessors and the witnesses. In cases when the reception of the disclosure is more ambivalent, Arie follows up the processing of the news a few days after the coming out. In any case, the end of each episode portrays 
Arie's final visit to the protagonist, taking place a couple of weeks after the disclosure: in these scenes the viewer learns about the 'postliminal' events and the changes the environment and the youngsters have gone through.

It is remarkable that the candidates normally take the second (and sometimes third) challenge more easily, even if the order of the coming out proceeds from the 'lightest' situations to those where the stakes are the highest for the youngsters. This may be imputable to the above generic structure, which provides certain keys to the participants about the 'proper conduct' of their subsequent disclosures. This proper conduct, as reflected in the format of the programme, entails certain inner preparation, including a preliminary weighing of the risk-benefit factors of the forthcoming act, contextualizing them by looking back on the previous struggles and the life situation in which the urge to come out has emerged. Furthermore, the candidate needs to find the right moment for a simple act of disclosure. The single episodes also suggest a step by step approach in terms of the order of the challenges the candidate intends to take.

The format of the programme thus provides a specific structure to the coming out practices. Besides this structure, there are also some other features that explicitly contribute to the dramatization of the process and thereby reinforce its ritual flavour. This ritualization can be captured for example in certain patterns of parlance: many protagonists motivate their coming out with the desire to 'become $a$ full person'. Others explicitly refer to their coming out as the last 'limen' that they need to cross. Arie as narrator generally refers to the challenge that the candidates take as an 'assignment' or 'mission' to be completed, and to the consecutive disclosures as (theatrical) 'acts'. It is also not infrequent that the timing of the coming out is connected to another important event, rite or significant moment in the protagonist's life: graduation, forthcoming world trip, the start of the freshman year or the last game of the season; this way, the latter event strengthens the passage-like nature of the former as well.

More generally, the explicit ritualization of the coming out can be most clearly captured in the representation of the protagonists' lives before and after the disclosure. Most of these depictions emphasize the integrative power of the ritual act, as it is manifested in the contrast between the struggles before the 'big step' and the situation that comes into being with the reincorporation of the protagonist into society. The boy who sometimes walks to the gay bar in his hometown but never dares to go in finally makes his entrance in the last scene. The youngster who wanted to have a relationship appears with his first partner at the follow-up meeting with Arie. The student who had been bullied in school before leaves the schoolyard hand in hand with his boyfriend at the end of his episode.

The above contrasts already suggest that coming out in the programme generally turns out positively, even if some members of the environment need some time for reconciliation. As the following sections will show, the camera presence plays an essential role in securing this outcome of the disclosures. The examination of the authoritative power of the media frame will also direct our attention towards more subtle mechanisms through which mediation transforms the crisis periods of coming out into the less ambiguous process of rite of passage. 


\section{‘I just can’t do it alone`: media authority and ritual transformation}

The previous paragraphs showed how the structure of the episodes and certain explicit patterns of ritualization channel the protracted process of coming out into a single event (or a relatively simple sequence of events), providing a sense of viable choreography for the otherwise unscripted conduct of the self-disclosure. Still, the intriguing question remains: why do people actually choose to come out on the programme, what do the motivations and the explanations of the participants tell us about the conception of the media as an effective ritual agent, and how are such conceptions reflected in the outcomes of the self-disclosures? In short: how does the mediated way of conducting coming out operate, and represented as a regulative and natural means of ritual transformation?

\section{Motivations and justifications}

The candidates generally give clear and more or less standard answers in the episodes about their motivations for coming out, framing them as a combination of moral obligation ('If I plan to live with my parents for long, I really need to tell them', 'I don 't want to live a double life anymore', 'I am tired of lying') and a key to achieving self-fulfilment ( 'I want to be accepted as / am' 'I want to be myself). But what about the reasoning behind coming out in the presence of a film crew?

The explanations for this, given either to Arie and the viewers or to the environment during the coming out situations, seem diverse at first glance, yet they show some meaningful commonalities. Candidates like Theo, Thijs and Frans explicitly acknowledge that they wanted to create a 'no way back' situation, given their previous failures to 'find the right moment' to come out. Others justify their choice by arguing that they did not dare to take this risky step without support: as Carlijn puts it, 'the challenge was too high without the camera'. Most typically, the youngsters simply admit that they just 'couldn't do it alone'.

Underlying the above explanations, three patterns maintaining and legitimizing the ritualizing power of the media frame can be identified. First, in situations where the camera serves to prevent the candidate from backtracking, the media appears as the ultimate authoritative force for the protagonists to undergo the forthcoming challenge, without changing their minds at the critical moment. In this respect, conducting the coming out with the camera embodies an interesting combination of voluntariness and compulsion, bringing to mind the distinction between the liminal and liminoid features of transformational rituals. Although rituals intrinsically contain the element of voluntariness since the actors have to accept the ritual rules dictated by social compulsion (cf. Rothenbulher, 1998), ritual theorists normally distinguish classical rites of passage from their contemporary incarnations. Traditional liminal rituals, like tribal initiations or the first communion in religious communities, inevitably apply to every individual in a certain life stage due to societal pressure, while participation in modern liminoid rituals is based on voluntary deliberation. Although the candidates, of course, voluntarily sign up to participate, and therefore their entire journey can be regarded as liminoid, the reasoning of many participants about creating a 'no way back' situation reinforces the liminal characteristics of the central phase of their passage, in which the media presence embodies the 'societal pressure' underlying classical rites of passage. 
Second, it is noticeable that several justifications include the expectation that the media presence will provide a protective context in which the stakes and risks associated with 'ordinary' coming out will be reduced. While unmediated coming out is undoubtedly an 'extraordinary' act, its specialness obtains by its very real and unpredictable consequences. When participants refer to the normal conduct of coming out as a challenge that they could not have risen to alone, their reasoning also implies that the mere presence of the camera is able to transform the everyday setting of coming out into an out-of-the-ordinary liminal space in which, due to its formality, the structural norms and constraints of everyday life do not apply.

Third, all the explanations emphasizing the inability of the participants to come out alone point towards a more general discursive reproduction of the notion of the 'mediated centre' (Couldry, 2003). In fact, the very idea that the media can assist in these coming out situations evokes the myth of media's social centrality. When one starts wondering why these youngsters seek support outside their 'real' environment to resolve their crises, the most productive question that should be posed is how the media operates in order to reinforce the claim that it offers the best alternative. To this question, the above myth appears to give a valid answer: in the choice of coming out with the camera, exactly the naturalization of this claim is reflected: the media is there to stand for the candidates, suggesting with its mere presence a wider societal support behind the participants' back in their endeavours.

\section{Transformational work}

In the 'follow up', normally shot a few weeks after the coming out scenes, the majority of the candidates appear as newly-born 'initiates': they are relieved, they are more free and open and they are about to start their 'real' lives. These changes are apparently due to the internal process the participants have gone through as well as to the sometimes gradual, but more often immediate acceptance by their environment. However, it is striking how strongly the former process is emphasized in the cases where the environment reacts unexpectedly well to the coming out. For example, when Manon tells her friends that she is lesbian, their reactions are absolutely positive: 'It is very good that you have told this... but you don't need the programme for that! For us, nothing will change at all.' 'But for me, you have to understand, this is really an issue' - replies Manon.

Emphasizing that nothing has changed with the coming out is not exceptional in the programme. Not only do the majority of the reactions include this affirmation, but also several coming out speeches, either by expressing the hope that the relationship will remain the same or by arguing that the protagonist is still the same person. The articulation of the lack of any change seemingly works against the ritualization of the coming out process, at least if we follow those Turnerian theorists who argue that rituals are inherently subversive and transformative, and thereby distinct from ceremonies, events functioning as the agents of bonding and the guardians of the status quo (cf. Grimes, 2000: 121125). This contradiction is, however, superficial: in fact, certain transformations always occur, without exception. As the example of Manon suggests, in instances when the environment apparently does not change, it is the candidate who is actually transformed.

Moreover, despite the recurring rhetoric of 'nothing will change', the majority of the episodes present an immediate metamorphosis in the attitudes of the community around the candidates. Telling examples of this immediate transformation are the depictions of 'tough' peer groups before and right 
after the coming out of their mates. Prior to the disclosure, the youngsters tell offensive jokes, express their aversion to homosexuality, or deny the possibility of having gays in their sports team. These youngsters normally also get interviewed after the coming out, and while facing the camera, they generally modify their previous standpoints ('I said before that there are no gays in our teams, but now I can tell that I actually thought so'), come up with an explanation for their former behaviour ('we sometimes make jokes, but they are just jokes'), or simply ignore their previous views and engage in a somewhat gawky, but 'politically correct' and appreciating talk about the difficulties of coming out. The regulative power of the camera presence is not only reflected in these directly provoked instances, but also in the immediate situations of coming out, especially when the coming out takes place in front of a larger public: these situations without exception end up with the only possible public reaction learned as appropriate after someone makes an announcement in the presence of cameras: clapping.

Without a doubt, these explicit, immediate transformations carry a certain utopian flavour: one may wonder about the permanent effects of the regulative power of the media in the case of the 15year-old Niek, who had constantly been bullied and was now being celebrated without reservations by his classmates in front of the camera. Yet utopianism is by no means alien from rituals, as far as they rather operate as the symbolic dramatizations of the ought to, the manifestations of how society should ideally work, than the representation of the societal order as it is (Rothenbuhler, 1998). This subjunctive mode of media-related rituals has been discussed earlier (see Cottle, 2006; cf. Sumiala, 2013: 9). In our case, however, the world of 'as if' created by the programme not only normalizes coming out (presenting its 'ordinariness' through the affirmative reactions and the standardization of the act by repetition), but also naturalizes the idea that the self-disclosure, if you do it with the camera, becomes a more or less safe endeavour. Still, the public nature of coming out in the programme is not always unproblematic, and as the following section will show, the contestation of publicity has certain consequences both for the authoritative operation of the media and for the functioning of the Uit de Kast coming out as a rite of passage.

\section{With or without camera? Media authority challenged and restored}

We have seen in the previous sections how the motivations and the reactions to coming out justify the presence of the camera at the self-disclosures and, consequently, how the utilization of the media frame is represented as a powerful means for ritual transformation. However, the involvement of the media does not always remain un-problematized. In fact, those episodes in which publicity is not at all addressed form the minority, and sometimes the camera presence becomes not only the facilitator, but the main source of the drama.

Such drama already emerges in the second episode, when Theo comes out during family dinner. While the confession is immediately followed by reassuring reactions from his siblings, his parents remain remarkably silent for many minutes. Then his father quietly remarks: 'I find this terrible'. In response, the rest of his family starts defending Theo - 'He was suffering' - but their father interrupts them: 'This is the situation, OK. But I did not expect my otherwise honest son to do it this way' - and turns a bit hesitantly to the camera - 'I can say this, can't I?' To save the situation, Arie intervenes: 'Why did you decide to do it this way?' In his defence, Theo not only admits that he had tried everything 
before to come out but never succeeded, but also argues that he found it important for others to see how difficult a task this is.

The conflict between the perceived private nature of the subject matter and the camera presence also recurs later on. For instance, the father of Carlijn refuses to react in front of the camera and therefore the crew stops shooting. As Carlijn admits a few days later in her video diary, her father found the situation very unpleasant and he still can't accept his daughter needing the cameras to come out as lesbian ${ }^{8}$.

It seems that these situations, while questioning the legitimacy of the camera presence, also undermine the regulative power of the media, and thereby work against the ritualization of the selfdisclosures. Yet this deconstruction of authority is quite consistent with the liminal 'betwixt and between' phase of transformational rituals - in which ordinary hierarchies and moral codes are typically suspended and transgressed - as long as this suspension is temporal. In this respect, the authoritative position of the media follows a similar trajectory in each 'problematic' episode, through its temporal suspension until its ultimate restoration. Without exception, those taking part in the 'conspiracy' finally gain absolution so that coming out in the programme becomes justified by the end of each episode. Theo's father, who initially gets upset about the camera presence (but note, he continues to cooperate with the media at the critical moment as well: 'I can say this, can't I?'), at the end modifies his standpoint: 'Everyone who watches this will realize that being gay is not a matter of choice, and this will make coming out easier for others' - pointing towards a common good, which goes beyond the personal interests, expectations and circumstances. This sacrifice for a greater good is also reflected in all those cases when the environment finally gives consent to the airing of the episode - like the parents of Corné, hoping that 'it will reach more religious people'. In other instances, it is the presentation of the positive developments in the life of the actors involved through which the authority of the media is finally reinstated.

The above examples show how the media operates as a powerful ritual agent even in situations when the camera presence is explicitly problematized, especially when publicity is legitimized by wider societal purposes. However, it is important to note that there are certain contexts in which this agency fails to work. This becomes clear from the episode of Robert who is followed by the production to his homeland, the Antillean island of Bonaire, where the coming out turns dramatically wrong. After the confession - made in a mixture of Dutch, Spanish and Papiamentu - Arie is unable to control the hysterical reaction of the mother. 'What do you want us to do?' - he asks Robert in his puzzlement, while the mother is still crying aloud in the background: 'No, I am going to die, tell them to leave!' 'I will try to talk to her again, and calm her down' - Robert says, taking the lead to save the situation that has got out of hand. The support aimed to be given by the media became impossible here, because the programme makers could not take up any authoritative position in the given cultural realm. Although the parents finally consented to the broadcast, the disclosure was not followed by any real catharsis, resolution, or reconciliation; Robert's case became one of those few where, besides presenting a passage, the ritual working of the media failed to transpose the coming out to a fully developed rite of passage.

And it is not only Robert's story where the re-integrative phase of the passage becomes impaired. In two other episodes, Corné and Derk-Anne get into a 'stalemate' coming out to their religious families. Although the parents empathize with their sons' struggles and accept their 
homosexual feelings, they stubbornly refuse the idea of 'translating' such feelings into 'practice'. In his follow-up meeting, Arie asks Derk Anne about his feelings. 'I am not really relieved... it feels doublesided.' 'I understand... you want to belong to the community, but on the other hand, they can't tell you what to do.' [The boy starts crying at this point, and Arie continues:] 'The big question is: how to get further? What will tomorrow bring? Or the day after tomorrow?'

These examples demonstrate that the deployment of media authority can only serve ritual transformation when it meets certain cultural prerequisites. Still, although the above instances fail to work as rites of passage, they can be considered important constituents of the ritual operation of the programme as a whole, as far as they contribute to the reproduction of the values and dominant ideologies for which the show appears to stand. This issue leads us to some final thoughts relating to the wider social space in which the programme is able to function as media ritual, addressing the ritual significance of Uit de Kast beyond the lives of those directly participating in the show.

\section{Media coming out and the wider social space: the politics of ritualization}

\section{The affirmation of 'our' values}

As mentioned in the introduction, the explicit purpose of the programme was twofold: helping young people struggling with their coming out, and showing in various contexts what these struggles entail. With this mission, the programme clearly embraces the notions of diversity and emancipation, two tropes that have become central to the national self-imagination and to the Dutch discourses on citizenship in the past forty years (cf. Mepschen et al., 2010). It is also easy to notice that the participants' individualistic explanations for their urge to come out (becoming themselves, achieving autonomy and self-fulfilment) are strongly anchored in this discourse of liberation. Looking at these aims of both the producers and the protagonists, it can be proposed that the basic tension on which the show capitalizes is the confrontation of the 'ideal' with the 'real': if rituals transmit collective messages to 'ourselves' (Leach, 1976: 45, cited by Baumann, 1992: 98), the difficulties with and ultimately the success or the failure of coming out on Uit de Kast testify to and communicate the extent to which these ideals have been achieved in Dutch society at large.

In this respect, the positive outcomes in the majority of the episodes seem to directly affirm these values. In cases when the youngsters encounter negative reactions, however, the social centrality of the values of tolerance, self-realization and inclusion are displayed in a different manner: by constructing hierarchical oppositions, in which the media and the protagonists always stand on the 'right' side. The stories of Robert, Corné and Derk-Anne bring this dialectic most sharply to the fore: the endeavours of the programme makers and the candidates in these instances are hindered by the environment, which is framed as 'traditional' or 'provincial', and serving in this way as the antithesis of the values for which the show stands. Such contrasts emerge, for example, by the juxtaposition of the vivid image of Amsterdam (where Arie first meets Corné) and the picture of the candidate's grey village, where the only sound to be heard is the church bell, and all the villagers wear Sunday clothes. When the 'otherness' of the 'problematic' environments is visually less palpable, it is constructed by the narration: 'He lives in a community where TV and pop music are barely accepted'. 'In her village in Zeeland, it is not 
usual to speak openly about homosexuality'. 'To this union the students are coming from different denominations, but they have one thing in common: they are all fanatically religious'. These oppositions recur several times in different forms, connecting the issue of coming out to wider contrasts between progress and backwardness, city life and the countryside, individualism and rigid communal structures, religiosity and homosexuality ${ }^{9}$. In doing so, coming out becomes the field of a symbolic battleground, where 'an imagined modern self' is framed 'against an imagined traditional other' (Mepschen et al., 2010: 970).

This process of 'othering' the environment to reinforce the dominant ideologies of inclusion and tolerance seems to be controversial; nevertheless, it underlines Baumann's assertion that rituals in plural societies necessarily implicate 'Others', and may be 'as much concerned with a message to, or about, 'Others' as with what Leach called "collective messages to ourselves"' (Baumann, 1992: 113). This concern of Uit de Kast is expressed most directly by including a documentary as a final episode to the program, titled Niet Uit de Kast ('Not Out of the Closet'), addressing the reasons why the producers could not find any Muslim participants for the show. However, while embracing the notion of emancipation, the program also reproduces an even more implicit mechanism of 'othering', emerging through the portraying of the protagonists against the categorical referent of 'other gays'.

\section{Diversification and homogenization: the production of 'homonormativity'}

This implicit process of 'othering' is most apparent in those episodes which also happened to receive the largest number of positive comments on the programme's website ${ }^{10}$, and where coming out as gay seems to be the least expected by the environment. Not only do the behaviour and appearance of these participants refute stereotypical images of gay effeminacy and flamboyance, but also the depiction of their daily activities: they listen to hardcore music, are successful athletes or huge paintball fans. More generally, all the youngsters selected for participation appear as 'guy - or girl - next door', with whom it is easy to sympathize. 'They could be you' - tells the depiction of this ordinariness, yet this depiction is not about the ordinariness of diversity - however you look like or act - but the reinforcement of the idea that these participants fit well into the (straight) societal order. This way, while the selection of the candidates in terms of social circumstances communicates the ideal of diversity, the characterization of the protagonists as gays actually reflects a wider assimilative strategy, frequently described as the development of 'homonormativity'11 (Duggan, 2002, cited by Mepschen et al., 2010).

This normalization is clearly articulated in several episodes. For instance, Daan, one of the most popular participants, makes the following remark at some point during his coming out: 'Not all gays are sissies, like those standing on the pride boats and dance ${ }^{12}$... it occurs everywhere, like in a football team.' - although his statement aims to be inclusive (pointing out that homosexuality is all around us), the distinction between the 'sissies' and him also implies a divisive stance towards 'other gays' in society at large.

Without doubt, this principle of 'gays are just like us' becomes problematic when critically addressing the recognition of difference in the depiction of the candidates (cf. Dhaenens 2012). Our point is, however, not to moralize about how the programme reproduces heteronormative structures, but to emphasize that such homogenization is essential for the ritual efficiency of the show, as far as the broader audience is concerned. Ritualization not only presupposes the maintenance of the sense that 
the staged performance speaks to 'all of us', but it also requires the reinforcement of a sense of communality with the participants and with the stakes dramatized throughout their ritual transformation. Ritualization, in this sense, is achieved by the programme through the simultaneous, yet reversed processes of diversification and uniformization: the diversity of the participants in terms of their circumstances reinforces the claim that the programme provides access to our shared social reality, while controlling the articulations of gay identities serves as the basis of identification with the participants for the imagined viewer. In this respect, framing the protagonists as 'ordinary' while following their endeavours plays an important role in channelling, socializing and normalizing 'gayness' in Dutch society; fulfilling this role may be considered one of the main functions of representing coming out in Uit de Kast as a rite of passage.

\section{Conclusion}

In order to offer an explanation for the increasing appeal to mediated coming out practices, this article investigated the ritualizing role of the media in the popular television programme Uit de Kast. Our analysis identified three major factors as the basis of the ritual power of the show. First, we showed how the programme creates a standardized, recurring structure to the acts, evoking analogies with the classical phases of rites of passage. Second, we demonstrated how media authority is deployed - or ultimately restored - in the episodes to present the media frame as an effective means of securing positive outcomes to the self-disclosures. Third, the analysis revealed how the authoritative operation of the programme is fed by the reinforcement of the dominant national values of tolerance and diversity, with the simultaneous process of channelling and normalizing the articulation of gayness. As we argued, these factors jointly contribute to the transformation of the ambiguous process of coming out into a legitimate ritual performance.

While this emergence of the coming out ritual offers a clear example of how media orders - and constructs - social practices, it also has to be noted that ritualization occurs in many forms and contexts in contemporary television culture. Several formats and genres utilize or build on ritualistic formulas (cf. Westerfelhaus and Lacroix, 2006) to present events, interactions and passages, and Uit de Kast shows similarities with many of them. For example, the 'before and after' structure of the programme, imposed on the process of coming out, follows the typical script of make-over reality shows. Similarly, the very act of disclosing deep, intimate secrets is not only common in trash talk shows, but also relates the hybrid format of Uit de Kast to the general tradition of 'confessional' television (see Aslama and Pantti, 2006). At the same time, what makes Uit de Kast less typical within the spectrum of 'reality rituals' is the staging of the stakes embedded in the action of coming out. As we have seen, not only are the individual and the social ultimately interwoven in these stakes, but - contrary to the stakes of more playful reality formats - they also embody the deepest existential concern that the protagonists as social beings may probably face: the disruption of their most important relations. The constant emphasis on these stakes throughout the programme undoubtedly contributes to the construction of coming out as a ritual of 'serious life' (cf. Rothenbuhler, 1998: 23-27). This 'seriousness' of the coming out ritual, as we have discussed, is also linked to the more general societal values which are tested, sometimes challenged, but ultimately always affirmed in the episodes - in this respect, the self-disclosure within Uit de Kast also departs from the monologist, 'first-person' tradition of confessional media rituals (cf. 
Aslama and Pantti, 2006). Moreover, since confession normally presupposes a 'sin' to be confessed, and coming out is presented by the programme rather as a passage through which one 'naturally' has to go through, the 'confession' in Uit de Kast is actually made by the environment: the reaction of the people around the protagonist to the disclosure testifies the extent to which they conform to the valued tradition of openness and tolerance.

However, while our analysis underlines the quintessential role of media in the construction of new forms of ritual life, one cannot lose sight of the fact that the self-disclosures, as presented in the programme, are staged performances. Accordingly, although our 'thick description' tends to confirm that coming out within Uit de Kast is certainly not the media presentation of a rite (i.e. of a pre-existing ritual act), at this point we can confidently state only that it is a presentation as a rite. Even if media texts as symbolic constructs may be the most central spaces for producing, shaping and maintaining the sense of order (Sumiala, 2013: 3) in contemporary mediatized societies, their analysis can speak first and foremost about these mechanisms of mediation, rather than providing incontestable statements about the mediated. In this sense, an analysis of mediated coming out focusing exclusively on the media text clearly has the limitations of grasping the dimension of ritual experience of those, who at various levels (as protagonists, as their environment, as production members, or as Dutch, straight or gay audiences), directly or indirectly participate in this media ritual. If ritual presupposes participation, and participation is articulated through performance, conceiving mediated coming out as ritual practice requires one to address a variety of questions, including: what constitutes on and off stage, and the time and the space of the ritual? How can we locate the actors and the audience in this space? What scripts dictate the performance? (Grimes, 2006: 13; cf. Sumiala, 2013: 8). This article aimed to be a first step by exploring the on-stage features of the coming out performances and the media script dictating their actualization. For the clarification of the off-stage significance of the programme, a more extensive study is currently being conducted, addressing not only the impact of the show on the unmediated lives of those involved, but also the question of how the example of Uit de Kast relates to, differs from, or shares common patterns with other forms of mediated coming out practices.

What the 'close reading' of the programme brought to the fore is, first, that Uit de Kast clearly deploys the 'myth of the mediated centre' (Couldry, 2003): the show not only builds on the notion that media is our access point to the social and its core values (by the claim of speaking for 'us': for the youth, for gays, for their relatives, for the Dutch), but by employing this myth, it also creates a public space in which the otherwise socially unscripted life-crisis situation turns into an ordered and culturally meaningful practice, implying also that the media frame - and the appropriation of its authority - is an effective, and probably the ultimate means of changing one's unmediated, everyday life.

Of course, the very idea that media indeed can help to organize and positively influence 'ordinary' lives is not unique to the claims of this particular programme. Rather, Uit de Kast exemplifies the wider naturalization of this notion in the current era of interactive, participatory media culture. The rapid transformation of our media-oriented behaviour in the past decades has generated important debates concerning the broader consequences of this ethos of participation, polarized around the questions of empowerment (e.g. Jenkins, 2006) and exploitation (cf. Andrejevic, 2004; van Dijck, 2009). We assert that the concept of ritual can offer a fresh input into these debates, by delivering culturally contextualized accounts of the intricate relationship between agency the regulative power of media. 
In so doing, it seems especially important to revisit the concept of media ritual, developed by Couldry more than a decade ago. Couldry's work primarily located media power in the restricted access to the 'media world' (2003). While the ritual boundaries of the media appear to be dismantled in this era, a new, more refined myth seems to have succeeded the old one: the 'myth of participation' (Author, forthcoming). At least, the ritualization of coming out within Uit de Kast not only suggests that this myth plays an increasingly prominent role in the construction of contemporary media rituals, but also underlines the timeliness of questioning the values and the experiences attached to media participation, beyond their discursive construction by media institutions and media texts. In this sense, this article has served for us as a point of departure towards this direction.

\section{References}

Alexander, J. and Losh, E. (2010) 'A YouTube of one's own?': 'Coming out' videos as rhetorical action. In: Pullen, C. and Cooper, M. (eds.) LGBT Identity and Online New Media. New York: Routledge.

Andrejevic, M. (2004) Reality TV: the work of being watched. Rowman and Littlefield Pub.

Aslama, M. and Pantti, M. (2006) Talking alone: reality TV, emotions and authenticity. European Journal of Cultural Studies, 9: 167- 184.

Baumann, G. (1992) Ritual implicates 'Others': rereading Durkheim in a plural society. In de Coppet, D. (ed.) Understanding Rituals. London: Routledge.

Bell, C. (2009) Ritual Theory, Ritual Practice. Oxford: Oxford University Press.

Coman, M. (2005) Cultural anthropology and mass media: a processual approach. In Rothenbuhler, E. W. and Coman, M. (eds.) Media Anthropology. Thousand Oaks: SAGE, 46-56.

Cottle, S. (2006) Mediatized rituals: beyond manufacturing consent. Media Culture Society, 28: 411-432.

Couldry, N. (2003) Media rituals: A critical approach. London: Routledge.

Couldry, N. (2006) Listening Beyond the Echoes: Media, Ethics and Agency in an Uncertain World. London: Paradigm Publishers.

Dayan, D. and Katz, E. (1992) Media events: The live broadcasting of history. Harvard University Press.

Dhaenens, F. (2012) Queer cuttings on YouTube: Re-editing soap operas as a form of fan-produced queer resistence. European Journal of Cultural Studies, 15: 442-456.

van Dijck, J. (2009) Users like you? Theorizing agency in user-generated content. Media, Culture \& Society, 31: 41-58.

Dow, B. (2001) Ellen, Television, and the Politics of Gay and Lesbian Visibility. Critical Studies in Media Communication, 18:2, 123-140

Drushel, B. (2010). Virtually Supportive: Self-Disclosure of Minority Sexualities through Online Social Networking Sites. In Pullen, C. and Cooper, M. (eds.) LGBT Identity and Online New Media, London: Routlege.

Gonsiorek, J. C. - Rudolph, J. R. (1991) Homosexuality: Research Implications for Public Policy. Sage

Grimes, R. (2000) Deeply into the Bone. Re-inventing Rites of passage. University of California Press. 
Grimes, R. (2006) Rite out of Place. Ritual, Media and the Arts. Oxford University Press.

Herdt, G. (1992) Gay Culture in America: essays from the field. Beacon Press.

Herman, D. (2005) 'I'm Gay': declarations, desires, and coming out on prime-time television. Sexualities, $8: 7$

Jenkins, H. (2006) Convergence Culture. Where Old and New Media Collide. New York: New York University Press.

Kuppens, A. and Mast, J. (2012) Ticket to Tribes: culture shock and the 'exotic' in intercultural reality television. Media, Culture \& Society, 34: 799-814.

Liebes, T. and Curran, J. (1998) Media, Ritual and Identity. London: Routledge.

Mepschen, P. - Duyvendak, J.W. - Tonkens, E.H. (2010) Sexual politics, orientalism and multicultural citizenship in the Netherlands. Sociology, 44: 962-979.

Mihelj, S. (2008) National media events. From displays of unity to enactments of division. European Journal of Cultural Studies, 11: 471-488.

Orne, J. (2011) You will always have to 'out' yourself: Reconsidering coming out through strategic outness. Sexualities, 14:681.

Reijnders, S. - Rooijakkers, G. - van Zoonen, L. (2007) Community spirit and competition in Idols. Ritual meanings of a TV Talent Quest. European Journal of Communication, 22: 275-292.

Reijnders, S. (2010) On the trail of 007: Media pilgrimages into the world of James Bond, Area

Reijnders, S. - Spijkers, M. - Roeland, J. - Boross, B. (2013) Close encounters: ritualizing proximity in the age of celebrity. An ethnographic analysis of meet-and-greets with Dutch singer Marco Borsato. European Journal of Cultural Studies, DOI: 10.1177/1367549413508098

Rothenbuhler, E. (1998) Ritual communication: From everyday conversation to mediated ceremony. United States: SAGE

Rothenbuhler, E. and Coman, M. (eds.) Media Anthropology, Thousand Oaks: Sage.

Sumiala, J. (2011) Reality on Circulation - School shootings, ritualized communication, and the dark side of the sacred. ESSACHESS. Journal for Communication Studies, vol. 4, no. 2(8)

Sumiala, J. (2013) Media and Ritual. Death, Community and Everyday Life. London: Routledge.

Turner, V. (1977) The Ritual Process. Cornell: Cornell University Press.

Westerfelhaus, R. - Lacroix, C. 2006. Seeing "Straight" through Queer Eye: Exposing the strategic rhetoric of heteronormativity in a mediated ritual of gay rebellion, Critical Studies in Media Communication, 23:5, 426-444. 


\section{Notes}

${ }^{1}$ For an overview and critical reflection on this perspective see for example Herdt, 1992; Herman, 2005; Orne, 2011.

2 This article was awarded the Best Paper Award of the annual conference of the Media, Communication and Cultural Studies Association (MeCCSA), organized around the theme 'Media and the Margins' in Bournemouth, UK, 2014.

${ }^{3}$ The first episode attracted more than 750,000 viewers and continued to produce high viewing figures for such a youth programme in the Netherlands (data received via Stichting Kijkonderzoek).

${ }^{4}$ For example, the programme Over mijn lijk ('Over my dead body'), following young people with terminal illness, or the anti-bullying programme Over de streep, designed to break down stereotypes and promote mutual respect among high-school students who participate in a 'Challenge Day'.

${ }^{5}$ http://www.vancouverunitarians.ca/cms/site/pid/304, accessed on 20 May 2013.

${ }^{6}$ The majority of the protagonists are male (13 out of 18), with an age between 15 and 27, but they differ remarkably in their social profile: there are candidates with divorced parents, high-school and university students, youngsters from the countryside and from different religious denominations, athletes, and young adults with disabilities. Furthermore, explicit efforts were made by the production to redress the 'gender balance' of the show, as it is reflected in the recruiting advertisements after the second season, specifically targeting female candidates (see for example: http://www.damespraatjes.nl/2012/arie-boomsma-zoekt-vrouwen-voor-kros-uit-de-kast, accessed on 24 June 2014). As a result, the majority of the participants of the last season were females.

${ }^{7}$ http://uitdekast.kro.nl, last accessed on 2 December 2013.

${ }^{8}$ Due to such conflicts, using the camera at the actual act of coming out becomes more and more optional during the course of the programme. Still, while this option presumably reflects the aim of the production team to avoid open confrontations, it is striking how the rhetoric which originally explained the employment of a 'cover story' ('In order to get honest reactions...') becomes altered for the justification of the lack of a camera in such 'optional' situations: 'In order to avoid fake reactions'.

${ }^{9}$ Without a doubt, the sharpest contrasts are portrayed when it comes to the conflict between religiosity and homosexuality. In this respect, the commonly known Catholic orientation of the broadcaster may serve as the basis of the legitimacy and the authenticity of the programme to critically address the issue.

${ }^{10}$ Based on a brief content analysis of a total of 513 entries.

11 This normalization refers, on the one hand, to how the popular representation of gay identities 'has changed from a deviant other to the mirror image of the ideal heterosexual' (Mepschen et al., 2010: 970). On the other hand, 'homonormativity' refers to a more general development of the normalization of gay identities, which, as argued by Mepschen and others, has resulted in the Netherlands in a depoliticized, domesticized, and consumption-based character of gay identities that 'no longer threaten but replicate and underscore heteronormative assumptions and structures' (idem).

${ }^{12}$ Referring here to the annual gay pride in Amsterdam, taking place on the canals of the city. 